\title{
Herding in Smart-Beta Investment Products
}

\author{
Eduard Krkoska ${ }^{1}$ and Klaus Reiner Schenk-Hoppé ${ }^{1,2, *}$ \\ 1 Department of Economics, School of Social Sciences, University of Manchester, Manchester M13 9PL, UK; \\ eduard.krkoska@student.manchester.ac.uk \\ 2 Department of Finance, NHH-Norwegian School of Economics, 5045 Bergen, Norway \\ * Correspondence: klaus.schenk-hoppe@manchester.ac.uk
}

Received: 26 February 2019; Accepted: 18 March 2019; Published: 21 March 2019

\begin{abstract}
We highlight herding of investors as one major risk factor that is typically ignored in statistical approaches to portfolio modelling and risk management. Our survey focuses on smart-beta investing where such methods and investor herding seem particularly relevant but its negative effects have not yet come to the fore. We point out promising and novel approaches of modelling herding risk which merit empirical analysis. This financial economists' perspective supplements the vast statistical exploration of implementing factor strategies.
\end{abstract}

Keywords: herding; factor investing; risk

JEL Classification: G12; G14; G40

\section{Introduction}

Factor-investing is the latest craze among asset managers. As most elegantly put by Bender et al. (2013, p. 2), a factor is "any characteristic relating a group of securities that is important in explaining their return and risk."

Investing according to factors, or "smart-beta" investing, began with Fama and French's (1992, 1993) Nobel-prize winning observation that a substantial proportion of equity returns can be explained by just three factors. As these and other factors yielding excess returns were discovered and gained significant academic attention, their use became adopted by financial managers, who promoted products such as the now popular smart-beta Exchange Traded Funds (ETFs). Practitioners claim that proper use of smart-beta tilts can provide around double the Sharpe ratio of a standard market-value weighted portfolio (Amenc et al. 2014). Famous hedge funds such as AQR Capital Management and Dimensional Fund Advisors are leading proponents of factor investing. The factor-investment industry has seen dramatic annual growth rates of $30 \%$ in the assets under management (AUM) in the past five years and at present manages more than $\$ 1$ trn according to the Economist $(2017,2018)$. A Financial Times Stock Exchange (FTSE) report ( Russell 2018, p. 6) finds that the percentage of investors explicitly using smart-beta strategies nearly doubled between 2015 and 2017. There is also a proliferation of factors used in such strategies. Wiggins (2018) reports there are now more than 300 different factors with about 40 factors being introduced annually. Cochrane (2011) famously referred to this as a "factor zoo".

As fund managers continuously attempt to outperform other funds, their factor strategies become more complex as well as controversial. This occurred firstly with the implementation of multi-factor strategies, which become more complex as there are meaningful correlations between variables. For example, Asness et al. (2013) mention the significant effects of this to Sharpe ratios ( Sharpe 1964, 1994). More recently, the debate is with regards to dynamic multi-factor strategies, where the factor weights are continually adjusted. Sundstrom (2018) defends its use by praising its ability to adjust 
throughout the business cycle, however the selectivity of the asset allocations hints that the investment style lean further towards active and away from passive.

The current paper aims to draw the attention of researchers and practitioners concerned with portfolio modelling and risk management to the potential risks emanating from investors herding into factor-strategies. We stress that this is a financial economists' perspective which contrasts with the vast statistical exploration of implementing factor strategies. For example, Allen and McAleer (2018) provided a comprehensive overview of the "Choosing factors" paper by Fama and French (2018). Despite the detailed statistical insights, the paper, along with many others which concern factors, does not mention risks of herding in popular strategies.

In this paper, we highlight a number of formal frameworks in which herding risk can be modelled as the risk emanating from changes in investor expectations, sluggish price movements or large and sudden cash flows. All of these are mostly unexplored, face difficulties in estimation, and are put forward as open problems for empiricists.

Financial history is littered with fashion turned to bust. (In)famous examples are the 1978 crash following herding in portfolio insurance, the dot-com bubble in 2000 and the more recent 2008 sub-prime lending crisis, all examples of crashes preceded by investors crowding in the financial markets ( Chincarini 2012, pp. 2-3). In our view, factors are at present a fashion (with innovation and creation of factors for the sake of generating business) and the lack of reflection that herding in innovative products is often followed by a downfall.

\section{Herding in Financial Markets}

Bikhchandani and Sharma's (2000, p. 4) review defines herd behaviour as: "an obvious intent by investors to copy the behaviour of other investors". It can be viewed as a rational ( Devenow and Welch 1996) or irrational (Welch 2000) bias that investors unwittingly succumb to. Herd behaviour is well documented in financial economics; for example, Wermers (1999) found herding behaviour from mutual funds, especially in certain categories of equity such as smaller firms and growth firms; Graham (1999) and De Bondt and Forbes (1999) found empirical evidence that financial analysts herd, with excessive agreement in their forecasting; and Roider and Voskort (2016) found evidence of investor herding in a laboratory experiment where reputational incentives arise.

\subsection{Risks of Herding}

In a seminal model of rational herding ( Banerjee 1992), a decision maker considers the behaviour of previous decision makers who may have important information; this theoretical framework finds that the behaviour of optimising agents is, in fact, to herd. This implies that if, for example, specialised institutions know that factors yield significant premia, then retail investors may follow their choices and herd in smart-beta products.

Using game theoretic principles, Caginalp et al. (2001) asserted that for the trading price to reflect fundamental value agents rely not only on their own optimisation, but on that of others. Once an overvaluation is observed, agents will have less certainty about the optimisation processes of other agents and may build on the trend, conditional on having enough cash. Once the excess cash and the upwards trend dissipates, the bubble can collapse in an abrupt and unpredictable manner.

Computational models have also been applied to determine the outcomes of herding behaviour. Duffy (2006) surveyed these types of models, which can involve reinforcement where higher yielding assets are purchased in larger quantity, whereas the reverse applies for poorly performing assets. Alternatively, belief-based learning models allow agents to form expectations about the strategies of other players in the market and then form their own strategy. The models can range from very unsophisticated expectation formation to perfect rationality.

Applying a model of agents with near zero intelligence, Duffy and Ünver (2006) found that this can stimulate asset price bubbles and crashes. Their results also match some features of experimental data from laboratory experiments, reinforcing the model's relevance to reality. 
Experimental evidence from Smith et al. (1988) finds that assets whose previous dividend payoffs were known would, on significant occasion, have their price inflated above fundamental value and then crash. This result held when the test subjects were experienced traders, although with a lower frequency. When the subjects participated repeatedly in the test, their deviations from intrinsic value became less pronounced as they learnt from the feedback. The test demonstrates that significant bubbles may emerge, even with experienced traders, if it is difficult to learn from feedback as is the case with new and evolving strategies.

In another experiment, Sgroi (2003) allowed for individuals' decisions to be endogenous, allowing them to take actions when they choose to, rather than forcing sequential decisions. This provides a more realistic experimental framework. Nevertheless, the choices of the first players alone were enough to convince others to herd, despite the option to wait and gather further information.

The literature clearly describes the risks that arise from herding in assets, whether it be return reduction or, more remarkably, asset price bubbles and resulting crashes. These kinds of situations are famous in financial history as the herding was not realised until it was too late.

\subsection{History of Herding}

In the 1987 financial bubble, which escalated far enough to crash suddenly, Norris (2012) reported that the Dow Jones index "lost $23 \%$ of its value". Portfolio insurance is often blamed, with the claim that it gave investors confidence that, if prices were exorbitant, they could exercise their insurance with minimal consequences. If stock prices fell, the institutions' computers would automatically sell futures of the market index, hence offsetting the loss of market decline. This dynamic hedging process was discussed in detail by Ho et al. (2013). Knowing that the insurance was available to them, large institutions watched market prices soar without considering the potential consequences of a large price drop.

What was seemingly not accounted for was that not all investors could simultaneously benefit from trading around a common market risk (Leland 1980, p. 581). To exercise the insurance and sell the futures, another investor must take the other side of the trade. Once stock prices began falling, a significant number of institutions began selling the futures. To sell such a large quantity of futures, their prices had to be driven down. Those buying futures also sold the underlying index to hedge their position, driving down prices further and causing further sales of the future contracts; this eventually resulted in the crash.

Whilst portfolio insurance should theoretically provide investors with further methods of optimising their trading strategy, rather than causing a crisis, Shiller (1988, p. 291) discussed "portfolio insurance as a fad". As this technological advancement itself should not have been sufficient to cause the stock market crash, Shiller discussed overconfident institutional investors, hinting at the acknowledgement of an overpriced market, contributed to by herding in portfolio insurance. A different model was proposed by Jacklin et al. (1992), where the market underestimates the amount of dynamic hedging being utilised, where in fact it is a fad, allowing asset prices to rise. It is only once the market realises the amount of herding in portfolio insurance that it reevaluates its asset pricing relative to fundamentals.

Another event of relevance to present-day smart-beta investing is the 2007 "quant meltdown", as discussed by Rennison and Wigglesworth (2017), whereby the renowned quantitative investment strategies failed, resulting in a financial crash. Whilst the use of these systematic strategies provides several benefits and opportunities, such as return enhancement and risk management, the applications of quant investing by large institutions was highly backed with leverage. There are debates on the exact root of the quant crisis, however there is some consensus that the combination of extreme leverage and crowding in the same trades led to it.

Whilst smart-beta funds are a quantitatively based method of generating returns, the methods are now much more diverse than a decade ago, with a plethora of alternative risk premia spanning asset classes and financial tools such as leverage, short-selling and derivatives and based around both, 
or either, return enhancement and risk management. This should reduce the risk of herding in the same strategies. However, in terms of implementation, it is likely for several large funds to be based around the same traditional factors, using less complex financial tools. In this case, there is a distinct possibility that these trades are, or will become, overly crowded.

This prospect was mentioned by Brightman (2011, p. 1) who argued that the quant meltdown "deserves more attention by today's investors", than the 2008 financial crisis, as it uncovers the risks that quantitative strategies entail. Relevant to today's fashion in smart-beta products, Brightman (2011, p. 2) claimed that "early success and clever marketing attracts large flows into the funds, which, in turn, drives the prices of securities held by these funds to unsustainable extremes".

Despite the striking similarities of herding in financial history with present-day smart-beta investing, the topic is often bypassed by those analysing the statistical properties of the investment style. The purpose of this paper is to highlight herding as a risk factor which ought to be considered and further investigated by financial economists and mathematicians.

\section{Smart-Beta Strategies}

Asset allocations based on factor strategies, most notably smart-beta Exchange Traded Funds (ETFs), are marketed as a combination of both active and passive management. Fund managers advertise their products as having the benefits of active strategies with the lower costs of passive index buying. ETFs have traditionally been a popular vehicle for passive investment, tracking an index and traded on a stock-exchange, with significantly lower management costs and more liquidity than active management ( Foucher and Gray 2014).

Active fund managers attempt to outperform the market for which they charge a higher fee. French (2008) concluded that the typical investor, under some assumptions, would be better off by switching to a passive portfolio. Furthermore, examining rising fees charged for active management, Malkiel (2013, p. 108) concluded that, "it is hard to think of any other service that is priced at such a high proportion of value".

\subsection{Foundations of Factor Investing}

The Capital Asset Pricing Model (CAPM) theory of linear market returns has significant documentation of anomalies. Early evidence can go back to Basu (1977), who found that portfolios with low $\mathrm{P} / \mathrm{E}$ ratios earned higher returns than those with higher ratios, on both a risk-adjusted and absolute basis. The now famous size effect, where risk-adjusted returns on small stocks were higher than those on large stocks, was first reported by Banz (1981). Reinganum (1981) showed that the outperformance related to both the $\mathrm{P} / \mathrm{E}$ ratio and size was not only short-term, but persisting over six months. The book-to-market, or "value", factor has also been well established ( Rosenberg et al. 1985), whereby the investor buys stocks with a high book-value to market-value ratio and sells stocks with a low ratio. The momentum strategy, buying stocks with recent high returns and selling those with low returns, was found to yield significant excess returns by Jegadeesh and Titman (1993). DeBondt and Thaler (1985) found a similar effect in timeseries: portfolios of prior "losers" tend to outperform prior "winners". The phenomenon is not short-term, as it is after thirty-six months that losing stocks earn significantly more than winners. These findings led to the first influential extension of the three-factor model by Carhart (1997), who added the short-term momentum effect as a fourth variable.

Seasonal anomalies are also examined. Thaler (1987b) found that stocks earned significantly higher returns in January than in other months. Thaler (1987a) found "Weekend, Holiday, Turn of the Month, and Intraday Effects". Thaler put forward several behavioural explanations for seasonality, such as the timings of both good and bad news being announced. He also wrote that most proposed explanations have been tested and rejected.

The seminal work of Fama and French (1993) identified five common risk factors that explain returns on both stocks and bonds. Making up the famous three-factor model, the stock factors are 
market risk, size and book-to-market value, whereas factors related to bond returns are default risk and a factor related to maturity. Doskov et al. (2016) found evidence, however, that aggregate risks in the macroeconomy, such as growth and volatility, not only have significant explanatory power but also dominate the size and value factors.

\subsection{The Factor Zoo}

As multifactor explanations of asset returns were further investigated in academia, Cochrane (2011) famously proclaimed that we now "have a zoo of new factors". One of the newly discovered factors was investment. Titman et al. (2004) found that firms which engaged in significant capital investment expenditures would experience lower stock returns for the next five years. Novy-Marx (2013) found that profitability, the ratio of gross profits to assets, was as good at explaining cross-sectional stock returns as the value factor. This strategy essentially buys productive stocks and sells unproductive stocks.

One of the latest asset pricing models is the Fama and French (2015) five-factor model, an extension of the three-factor model ( Fama and French 1996). The extended model now includes an operating profitability factor; stocks with robust profitability minus those with weak profitability. The final factor is investment; stocks with conservative investment minus aggressive investment stocks. An important result of Fama and French $(2015$, p. 10) is that the "five-factor model outperforms the Fama and French three-factor model on all metrics and it generally outperforms other models". It was estimated to explain $71-94 \%$ of cross-sectional expected returns variation for the portfolios examined. Despite this, the authors observed that the value factor was made redundant in this new model, with its explanatory power being captured by the other variables.

Factor investing has become so widespread that Johnson et al. $(2016$, p. 3) reported that, "as of 31 December 2015, there were 950 such products that seek to either improve return or alter risk relative to more-traditional market benchmarks". The number of smart-beta products today is even higher.

\subsection{Implementation}

While we are concerned with conscious smart-beta strategies, it is important to point out that unconscious factor investing is possible. An early example of exposure to systematic factors is illustrated by examining one of the largest institutional investors globally, Norway's government pension fund Norges Bank Investment Management (NBIM) with about $\$ 1$ trillion under management in 2019. An analysis of the fund's returns by Ang et al. (2009, p. 16) found that a significant part of the active return was "linked to a number of well-recognized systematic factors". In fact, when looking at the factor exposure of active returns, for both fixed-income assets and equity, about $70 \%$ of those returns were explained by 10 commonly known factors. Following these reports, NBIM took a more conscientious approach to factors in their investments ( NBIM 2009).

Robeco (2018), an international asset management firm with EUR 165 billion AUM, EUR 55 billion based on Quant models, provides a "Guide to factor investing in equity markets", describing a spectrum of smart-beta strategies, from low managerial discretion to high. A low discretion investment could be a single factor ETF, whereas a high discretion investment could be bespoke to the investors preferences. Objectives can include both return enhancement and risk reduction. The different objectives factor investing can take is reflected in the array of smart-beta ETFs available for purchase. For example, they vary in asset class, with some utilising fixed income and others currencies. There is also geographic variation, using emerging markets for example.

Many details of implementation are fiercely debated amongst practitioners, such as factor timing (see, for example, Robeco (2017), Asness (2016), and Arnott et al. (2016)). Another implementation challenge is multifactor allocations, for which Asness et al. (2015, p. 45) found evidence that, with value, momentum, carry and defensive strategies, "combining all four style premia into one portfolio effectively doubles the maximum Sharpe ratio obtainable from any single-style strategy". 


\section{Risk in Smart-Beta Portfolios}

There is a plethora of work detailing statistical insights on smart-beta strategies (for example, Allen and McAleer (2018)). This section describes the implications of herding, promising models of herding risk and data snooping in smart-beta.

\subsection{Evidence of Smart-Beta Herding}

An explanation of why herd behaviour might be prevalent in smart-beta funds is the (ir)rationality of managers to follow other managers' decisions. Scharfstein and Stein (1990) discussed how reputational concern could incentivise ignoring private information; if they are wrong it is easily justifiable, as the others were wrong also. Scharfstein and Stein (1990, p. 466) called this the "sharing the blame effect". Similarly, Zwiebel (1995) found there are disincentives to use innovations which dominate the industry norm. In fact, it may now be the case that not utilising factor tilts situate managers outside of the norm. There is importance in the reputations of innovators ( Katz and Shapiro 1985). Weaker reputation firms favour product compatibility with the high reputation ones. Market leaders being followed in their innovations can be related to big funds' use of factor strategies (such as NBIM discussed above) with smaller funds jumping on the bandwagon. This is especially likely as the early literature on smart-beta was overwhelmingly positive.

Taking a less rational approach to herding, early experimental tests about group thinking (Asch 1955) found that test subjects were highly suggestible to the answer of the majority. Lone managers may not want to disagree with the larger group, potentially on the belief that the group must be correct or that they do not want to be viewed as managers who are failing to utilise the best practice. Asness (2015) mentioned that one risk of smart-beta investing when strategies are well known, as is the case for many traditional factors, is that they may be especially "painful" to the investor in bad times. In bad times, for example, all investors can move cash to reduce this factor bet. The shifting of such a large volume of cash is strikingly similar to our previous example of the Quant crisis. When investors move cash flows synonymously the high volume of trade can in itself be thought of as a risk factor; the risk that in bad times there is a crash on a factor strategy. Asness (2015, p. 2), in fact, compared the "pain" in bad times to be something as bad as career ending.

We provide a formal framework which includes the flow risk of herding in smart-beta, however what this paper highlights is the lack of empirical work in measuring this herding risk. We suggest further empirical research in estimating this.

\subsection{Promising Modelling Approaches}

Herding as extreme capital movements. Herding in the overall market, investment strategies or specific products can be interpreted as extreme flows of capital. Asness (2015) put forward this view in his narrative of how alpha (excess returns due to investor skill) turns into beta (a risk premium that everyone can reap). The increased volatility due to the possibility of extreme flows of capital, in particular the drawdown, should be a risk factor and thus priced in an efficient market.

Empirical analysis could start from Carhart's (1997) four-factor model

$$
R_{i}-R_{f}=\alpha_{i}+\beta\left(R_{M}-R_{f}\right)+b_{s} S M B+b_{v} H M L+b_{m} U M D+\epsilon_{i}
$$

and add a risk factor related to capital flows. Such a factor would have to measure the correlation of a specific strategy $i$ 's capital flows and variations in the total market capitalisation.

Several issues in estimating this risk seem to be relevant. First, one should expect an asymmetry between the pattern of outflows and inflows of capital. Just as for the overall stock market, downturns tend to be more rapid than upturns (for example, see Terrones et al. (2011) and Graham (2006, p. 69)), which are particularly pronounced for specialised firms ( Opler and Titman 1994). When focusing on a particular investment strategy, one has to disentangle its capital flow and the overall flow in or out of the market. More poetically, one has to account for the old adage "the tide raises all boats". Second, 
extreme flows are rare events. It is unlikely that flows on most days are distinguishable from noise and thus constitute diversifiable risk, which is not rewarded with a risk premium. Perhaps lessons from catastrophe insurance (see Michel-Kerjan (2010)) can be useful to define a suitable factor for the model in Equation (1). Third, the relation between capital flows and the existing risk factors needs to be assessed. For instance, a momentum strategy reaping the UMD premium should suffer from larger inflows as it bids up prices on the long leg and depresses those on the short leg, and the reverse for outflows. However, outflows are highly dependent on past performance (reference here), which creates another estimation problem in properly disentangling dependent and independent variables.

Herding as toxicity. Research on the toxicity of order flows by Easley et al. (1996) might hold useful lessons for empirical research on risk premium due to herding. Their research considers the pricing behaviour of market makers in response to imbalances in the flow of buy and sell market orders and to changes in the frequency of order arrival.

In this type of model, traders may have information on future stock prices (news) but market makers, who set bid and ask prices and offer liquidity, have not. In an efficient market, the price of a stock at time $t$ is given by

$$
E\left[S_{i} \mid t\right]=P_{\text {no news }}(t) S_{i}^{*}+P_{\text {bad news }}(t) \underline{S}_{i}+P_{\text {good news }}(t) \bar{S}_{i}
$$

where bad news means the next period's stock price will be lower than today $\left(\underline{S}_{i}\right)$ and good news the opposite $\left(\bar{S}_{i}\right)$. The value $S_{i}^{*}=\delta \underline{S}_{i}+(1-\delta) \bar{S}_{i}$ is the value of the stock before any trading. The market maker also has ex ante beliefs $P$. on the probability of future outcomes. These beliefs will change in response to the observed order flow. If market-making is perfectly competitive, then bid and ask prices are set such that market makers' profits are zero:

$$
\begin{aligned}
\operatorname{Bid}(t) & =E\left[S_{i} \mid t\right]-\frac{\mu P_{\text {bad news }}(t)}{\epsilon+\mu P_{\text {bad news }}(t)}\left(E\left[S_{i} \mid t\right]-\underline{S}_{i}\right) \\
\operatorname{Ask}(t) & =E\left[S_{i} \mid t\right]+\frac{\mu P_{\text {good news }}(t)}{\epsilon+\mu P_{\text {good news }}(t)}\left(\bar{S}_{i}-E\left[S_{i} \mid t\right]\right)
\end{aligned}
$$

where $\mu$ is probability that an informed trader arrives and $\epsilon$ is probability that an uninformed order arrives. Often in the literature the latter are called noise traders or liquidity traders, i.e., their trade does not contain information but occurs for exogenous reasons. Calibrating these models is a tricky exercise. However, the main underlying idea is simple. If the orders execute much more often on one side of the market than the other (compared to the marker makers' expectations), then bid and ask can move dramatically. The order flow is toxic.

These models can be interpreted as looking at herding on a micro-scale. It could therefore be possible to carry out related analyses on a macro-scale. Most recently the model (which does not capture today's limit order book markets for stocks) has been modified for a world with high-frequency trading ( Easley et al. 2012) and also been applied to the 2010 flash crash (Easley et al. 2011). On the most extreme end of toxicity, one might place rare events (Nassim Taleb's famous black swan). Methods from extreme value theory, such as those highlighted by Singh et al. (2013) in connection with modelling the market events around the 2008 financial crisis, remain unexplored for their potential in modelling sudden shifts in capital allocations. Using these types of models to combine herding and risk premia on capital flows might be a challenging but interesting and fruitful future research problem.

Herding in agent-based models. Agent-based modelling forms a class of approaches that explicitly aim to study herding and market overreaction. There is a wide variety of theoretical approaches ( Hens and Schenk-Hoppé 2009) as well as computational methods (Tesfatsion and Judd 2006) for these models. The models that seem to have the greatest potential for combining herding and risk premia are those dealing explicitly with expectations dynamics (for their potential to generate booms and busts) and those using sluggish adjustment of prices (for their potential to generate fat tails and volatility clustering). 
Hommes (2013) and Hommes and Wagener (2009) presented many agent-based models in which the price of a risky asset is driven by expectations. In a model with one risky and one risk-free asset, economic agents with mean-variance utility and heterogeneous expectations about future price movements interact. The market price is determined in each period by finding a price that gives zero aggregate excess demand. The price of the risky asset is given by

$$
p_{t}=\frac{1}{1+r}\left[\sum_{h=1}^{H} n_{h t} E_{h t}\left(p_{t+1}+d_{t+1}\right)-a \sigma^{2} z^{s}\right]
$$

where $r$ is the risk-free rate, there are $H$ different types economic agents, each type has individual expectations $E_{h t}\left(p_{t+1}+d_{t+1}\right)$ over the next period price $p_{t+1}$ and the expected dividend $d_{t+1}$. The parameter $a$ is a common risk aversion against variance, $\sigma^{2}$ is the volatility of the risky asset and $z^{\mathcal{S}}$ is the exogenous total supply (shares issued).

Herding in the model coincides with sudden shifts in expectations. It is a demanding task to make this type of model work empirically. First, one has to devise a more parsimonious specification of expectations. Second, if herding were partly predictable, one could use futures and option prices to extract expectations. In general, it is unclear at present which data would be useful in deriving these expectations.

There has been progress along these lines in simpler models (e.g., by Lux (2009) and Chiarella et al. (2009)). These models are based on sluggish adjustment of prices. Consider for instance the simple dynamics of gradual price adjustment and expectations in (Lux 2009, Equations (3.10)-(3.13)). In this continuous-time model (simplified here), the price of an asset adjusts as

$$
p_{t}^{\prime}=\lambda\left(P_{f}-p_{t}+\pi\right)
$$

where $\lambda$ measures the speed at which the price reacts to changes in demand, $P_{f}$ is the price expected by fundamental investors, and $\pi$ are the expectations of trend-following investors. The expectations of the latter evolve as:

$$
\pi_{t}^{\prime}=c\left(p_{t}^{\prime}-\pi\right)
$$

where $c$ measures the aggressiveness of trend-followers. Alfarano et al. (2005) calibrated such a type of model to stock market and commodity indexes. They could fit fat tails of the return distribution and volatility clustering using a herding mechanism similar to Kirman (1993). To the best of our knowledge, there has not been any work done in the direction of combining that framework with the analysis of risk premia.

Financial market models with explicit capital flows. Another class of heterogeneous agent models that seems to have potential for calibration and the extraction of a herding risk factor was given by Hens and Schenk-Hoppé (2018). The view put forward there is to model financial markets explicitly in terms of the investment strategies present in the market and their wealth under management as well as a flow of capital between these strategies.

The basic model proceeds in two steps: (1) dynamics consisting of portfolio choice, random payoffs, determination of market prices and realised gains and losses; and (2) a flow of capital based on difference in realised returns or other characteristics. There are $K$ different dividend-bearing assets, a risk-free bond (labelled asset number 0 , with net interest rate $r$ ), and $I$ different investment strategies with initial capital $w_{0}^{i}$. The strategies are written in terms of proportions

$$
\lambda_{t}^{i}=\left(\lambda_{t, 0}^{i}, \ldots, \lambda_{t, K}^{i}\right)
$$

Asset prices are endogenous, determined by demand and supply:

$$
p_{t, k}=(1-c) \sum_{i=1}^{I} \lambda_{t, k}^{i} w_{t}^{i}
$$


where $c$ can be interpreted as a consumption rate. The portfolio at time $t$ is therefore given by

$$
\theta_{t, k}^{i}=(1-c) \lambda_{t, k}^{i} w_{t}^{i} / p_{t, k}
$$

and the bond investment is $\theta_{t, 0}^{i}=(1-c) \lambda_{t, 0}^{i} w_{t}^{i}$. The random dynamics of wealth is obtained as

$$
w_{t+1}^{i}=\sum_{k=1}^{K}\left[p_{t+1, k}+D_{t+1, k}\right] \theta_{t, k}^{i}+(1+r) \theta_{t, 0}^{i} .
$$

with $D_{t+1, k}$ the dividend paid to shareholders. $w_{t+1}^{i}$ comprises the wealth under management of strategy $i$ after asset payoffs (dividends and interest) are received and capital gains or losses occurred.

Now, reallocation of capital happens. The amounts are subject to a process of withdrawal and redistribution (typically depended on difference in realised performance). Denoting by $\pi_{t}^{i}$ the proportion of capital withdrawn from strategy $i$ and by $q_{t}^{i}$ the proportion of the total capital available for reallocation to flow to strategy $j$, the new distribution of wealth across the strategies is given by:

$$
W_{t+1}^{i}=\left(1-\pi_{t}^{i}\right) w_{t+1}^{i}+q_{t}^{i} \sum_{i=1}^{I} \pi_{t}^{i} w_{t+1}^{i}
$$

All of these equations can be combined in one stochastic non-linear dynamic model as:

$$
\begin{aligned}
W_{t+1}= & {\left[\operatorname{Id}-(1-c) \Theta_{t} \Lambda_{t+1}\left(\operatorname{diag}\left(\pi_{t}\right)+q_{t}\left(\mathbf{1}-\pi_{t}\right)^{T}\right)\right]^{-1} \times } \\
& {\left[\Theta_{t} D_{t+1}+(1+r)(1-c) \operatorname{diag}\left(\lambda_{t, 0}\right)\left[\pi_{t} \circ W_{t}+q_{t-1}\left(\mathbf{1}-\pi_{t}\right)^{T} W_{t}\right]\right] }
\end{aligned}
$$

where $\Theta_{t}$ is the matrix of portfolios at time $t$ with individual entries $\theta_{t, k}^{i}$.

The empirical challenge is to define investment strategies (a "market ecology") that captures a major part of the capital in the market. Further, one needs to devise and estimate the functions governing the flow of capital between different strategies. Strategies could be passive or active, e.g., based on Fama-French factors, or use information on the holdings of large institutional investors and hedge funds. Modelling this risk factor as a flow is novel and the severity of consequences from the risk is why we provide a framework from which empiricists can make estimates.

\subsection{Consequences of Smart-Beta Herding}

Potential consequences of herding in smart-beta products are closely related to several other instances of herding in financial markets. Discussing the practical implications of herding, Olsen (1996) suggested that it increases the mean of forecast earnings and reduces the variance of its distribution. As "more optimistic forecasts are usually better for the investment business than less optimistic forecasts" ( Olsen 1996, p. 38), the reduced variance can be explained by forecasts being shifted towards other managers' forecasts. If earnings forecasts are consistently above realised earnings, there will be a reduction in returns when asset prices inevitably adjust downwards.

Factor strategies being reported as a financial innovation may be a case of Shiller's (2010) "irrational exuberance", a concept especially important from the financial economist's point of view. Money flowing into the sector could, incorrectly yet intuitively, be viewed as a signal that it is economically sound, initiating herd behaviour. The generally positive economic picture of recent years has likely also fuelled confidence in the strategies, which have been performing well, but under good circumstances. Theoretical work ( Hens and Schenk-Hoppé (2018)) also finds evidence that, if value investors are patient, a likely scenario, then not only does the market incur significant price volatility but also both short- and long-term mispricings can occur. Brightman (2011) stressed that the 2007 quant meltdown is all but forgotten in light of the 2008 financial crisis. However, that is at investors' peril as the quant meltdown uncovered the risks that quantitative strategies entail and 
the role of success and marketing to attract large inflows of capital which eventually carry the seed to destruction. Smart-beta products are fashionable as never before and investors do not take into account potential herding into the same strategies, which may become overvalued and near capacity. Moreover, estimations of capacity are varied and by no means exact.

We can consider two cases: (1) investors all realise that there is an overvaluation and that capacity is nearing, resulting in a sharp decline in value of these strategies; and (2) capacity is reached, perhaps at a lower-bound estimate and a crash follows. Asness $(2015$, p. 5) frankly acknowledges that "on the risk side it seems clear, and pretending otherwise would hurt not help, that crises or runs on these strategies are more possible now that they're well known".

\subsection{Data Snooping}

Novy-Marx (2014, p. 137) quipped that "the party of the US president, the weather in Manhattan, global warming, the El Niño phenomenon, sunspots, and the conjunctions of the planets all have significant power predicting the performance of popular anomalies". The lesson here is that, if the methods used to discover factor relationships are believed, then these, seemingly spurious, relationships should also be believed. Overfitting was also discussed by Novy-Marx (2015, p. 2), who simultaneously employed multiple stock-level characteristics to produce high in-sample returns. His results indicate that, "the sorting variables (i.e., the random signals) have no real power, but strategies based on combinations of the 'signals' perform strongly". Hence, the performance of some factor models in backtesting does not indicate any future explanatory power of the models.

Considering data-snooping, Harvey et al. (2015) tested for the significance of 316 factors. Their analysis suggests that the majority of published factor relationships are significant only by chance and that, "there are only a handful of true systematic risk factors" ( Harvey et al. 2015, p. 33). Historically validated factors, such as market, value, low volatility, liquidity and momentum, are significant, whilst newer factors tend not to be. This yields the critical question of whether the relationships published are indeed true or exist by chance. Early concern of $p$-hacking was discussed in a famous medical article, "Why Most Published Research Findings Are False" by Ioannidis (2005). The severity of the issue is further documented by fact that the American Statistical Association issued a statement on $p$-values ( Wasserstein and Lazar 2016).

$\mathrm{Li}$ and West (2017) found that the performance of backtests is far superior to a smart-beta index once it becomes live. They blamed, at least partially, data snooping as backtests which are insignificant are far less likely to be published. Another claim is that the lower performance of live indices is due to backtests ignoring significant transaction costs, both explicit and implicit.

\section{Conclusions}

Smart-beta investments have enjoyed very positive press and academic backing. For example, Amenc et al. (2014) wrote that proper use of smart-beta tilts can provide around double the Sharpe ratio of a standard market-value weighted portfolio. Whilst factor rewards certainly have theoretical underpinning and statistical evidence to back them up, we write this as a warning to look further ahead in these investments. We have provided historical examples of herding in financial markets as well as reasoning why there may be herding into smart-beta products. This paper also highlights the rapidly expanding factor zoo, where many documented anomalies have little theoretical underpinning and may be the result of data snooping.

Several modelling approaches, all of them in their infancy with regards to empirical application, are emphasised. Modelling herding risk is accompanied with many empirical challenges, but is worth pursuing by those who have so far ignored this risk factor. Due to the severity of its consequences, this paper argues that the risk of herding into an investment style is one which ought to be considered by all practitioners in their risk analysis and portfolio modelling. 
Author Contributions: The authors have contributed jointly to all sections of the paper.

Funding: This research was funded by The University of Manchester SEI programme.

Acknowledgments: We would like to thank the three anonymous referees for their helpful comments and suggestions. The authors are responsible for any remaining errors or shortcomings.

Conflicts of Interest: The authors declare no conflict of interest.

\section{References}

Alfarano, Simone, Thomas Lux, and Friedrich Wagner. 2005. Estimation of agent-based models: The case of an asymmetric herding model. Computational Economics 26: 19-49. [CrossRef]

Allen, David E., and Michael McAleer. 2018. 'Choosing Factors' by Fama and French (2018): A Comment. Available online: https:/ / ssrn.com/abstract=3272608 (accessed on 1 February 2019).

Amenc, Noël, Felix Goltz, Ashish Lodh, and Lionel Martellini. 2014. Towards smart equity factor indices: Harvesting risk premia without taking unrewarded risks. The Journal of Portfolio Management 40: 106-22. [CrossRef]

Ang, Andrew, William N. Goetzmann, and Stephen Schaefer. 2009. Evaluation of Active Management of the Norwegian Government Pension Fund-Global. Available online: https:/ /www0.gsb.columbia.edu/faculty/ aang/papers / report\%20Norway.pdf (accessed on 1 October 2018).

Arnott, Robert, Noah Beck, and Vitali Kalesnik. 2016. Timing 'Smart Beta' Strategies? Of Course! Buy Low, Sell High! Available online: https:/ /ssrn.com/abstract=3040956 (accessed on 1 October 2018).

Asch, Solomon E. 1955. Opinions and social pressure. Scientific American 193: 31-35. [CrossRef]

Asness, Clifford S. 2015. How Can a Strategy Still Work If Everyone Knows About It? Greenwich: AQR Capital Management.

Asness, Clifford S. 2016. The siren song of factor timing. The Journal of Portfolio Management 42: 1-6. [CrossRef]

Asness, Clifford, Antti Ilmanen, Ronen Israel, and Tobias Moskowitz. 2015. Investing with style. Journal of Investment Management 13: 27-63.

Asness, Clifford S., Tobias J. Moskowitz, and Lasse Heje Pedersen. 2013. Value and momentum everywhere. The Journal of Finance 68: 929-85. [CrossRef]

Banerjee, Abhijit. 1992. A simple model of herd behavior. The Quarterly Journal of Economics 107: $797-817$. [CrossRef]

Banz, Rolf W. 1981. The relationship between return and market value of common stocks. Journal of Financial Economics 9: 3-18. [CrossRef]

Basu, Sanjoy. 1977. Investment performance of common stocks in relation to their price-earnings ratios: A test of the efficient market hypothesis. The Journal of Finance 32: 663-82. [CrossRef]

Bender, Jennifer, Remy Briand, Dimitris Melas, and Raman Subramanian. 2013. Foundations of Factor Investing. Available online: https:/ / ssrn.com/abstract=2543990 (accessed on 1 October 2018).

Bikhchandani, Sushil, and Sushil Sharma. 2000. Herd Behavior in Financial Markets: A Review. Washington, DC: International Monetary Fund.

Brightman, Chris. 2011. The Trouble with Quants. Research Affiliates Newsletter, August 4.

Caginalp, Gunduz, David Porter, and Vernon Smith. 2001. Financial bubbles: Excess cash, momentum, and incomplete information. Journal of Psychology and Financial Markets 2: 80-99. [CrossRef]

Carhart, Mark, and Sheridan Titman. 1997. On persistence in mutual fund performance. The Journal of Finance 52: 57-82. [CrossRef]

Chiarella, Carl, Roberto Dieci, and Xue-Zhong He. 2009. Heterogeneity, market mechanisms, and asset price dynamics. In Handbook of Financial Markets: Dynamics and Evolution. Amsterdam: North Holland, Chp. 5, pp. 277-344.

Chincarini, Ludwig B. 2012. The Crisis of Crowding. Hoboken: John Wiley \& Sons.

Claessens, Stijn, M. Ayhan Kose, and Marco E. Terrones. 2011. Financial cycles: What? how? when? NBER International Seminar on Macroeconomics 7: 303-44. [CrossRef]

Cochrane, John H. 2011. Presidential address: Discount rates. The Journal of Finance 66: 1047-108. [CrossRef]

De Bondt, Werner, and William P. Forbes. 1999. Herding in analyst earnings forecasts: Evidence from the United Kingdom. European Financial Management 5: 143-63. [CrossRef] 
De Bondt, Werner, and Richard Thaler. 1985. Does the stock market overreact? The Journal of Finance 40: 793-805. [CrossRef]

Devenow, Andrea, and Ivo Welch. 1996. Rational herding in financial economics. European Economic Review 40: 603-15. [CrossRef]

Doskov, Nikolay, Tapio Pekkala, and Ruy Ribeiro. 2016. Tradable Aggregate Risk Factors and the Cross-Section of Stock Returns. Available online: https:/ / ssrn.com/abstract=2200889 (accessed on 1 October 2018).

Duffy, John. 2006. Agent-based models and human subject experiments. In Handbook of Computational Economics, Volume 2, Agent-Based Computational Economics. Amsterdam: North Holland, chp. 4.

Duffy, John, and M. Utku Ünver. 2006. Asset price bubbles and crashes with near-zero-intelligence traders. Economic Theory 27: 537-63. [CrossRef]

Easley, David, Nicholas M. Kiefer, Maureen O'Hara, and Joseph B. Paperman. 1996. Liquidity, information, and infrequently traded stocks. The Journal of Finance 51: 1405-36. [CrossRef]

Easley, David, Marcos M. López de Prado, and Maureen O'Hara. 2011. The microstructure of the flash crash: Flow toxicity, liquidity crashes, and the probability of informed trading. Journal of Portfolio Management 37: 118-28. [CrossRef]

Easley, David, Marcos M. López de Prado, and Maureen O'Hara. 2012. Flow toxicity and liquidity in a high-frequency world. The Review of Financial Studies 25: 1457-93. [CrossRef]

Economist. 2017. Building a beta mousetrap. Buttonwood. The Economist 422: 9032.

Economist. 2018. "Factor investing" gains popularity. The Economist 414: 9074.

Fama, Eugene F., and Kenneth R. French. 1992. The cross-section of expected stock returns. The Journal of Finance 47: 427-65. [CrossRef]

Fama, Eugene F., and Kenneth R. French. 1993. Common risk factors in the returns on stocks and bonds. Journal of Financial Economics 33: 3-56. [CrossRef]

Fama, Eugene F., and Kenneth R. French. 1996. Multifactor explanations of asset pricing anomalies. The Journal of Finance 51: 55-84. [CrossRef]

Fama, Eugene F., and Kenneth R. French. 2015. A five-factor asset pricing model. Journal of Financial Economics 116: 1-22. [CrossRef]

Fama, Eugene F., and Kenneth R. French. 2018. Choosing factors. Journal of Financial Economics 128: $234-52$. [CrossRef]

Foucher, Ian, and Kyle Gray. 2014. Exchange-Traded Funds: Evolution of Benefits, Vulnerabilities and Risks. Bank of Canada 4: 34-46.

French, Kenneth R. 2008. Presidential address: The cost of active investing. The Journal of Finance 63: 1537-73. [CrossRef]

Graham, Benjamin. 2006. The Intelligent Investor. New York: HarperCollins.

Graham, John R. 1999. Herding among investment newsletters: Theory and evidence. The Journal of Finance 54: 237-68. [CrossRef]

Harvey, Campbell R., Yan Liu, and Heqing Zhu. 2015. ... and the cross-section of expected returns. The Review of Financial Studies 29: 5-68. [CrossRef]

Hens, Thorsten, and Klaus R. Schenk-Hoppé, eds. 2009. Handbook of Financial Markets: Dynamics and Evolution. Amsterdam: North-Holland.

Hens, Thorsten, and Klaus R. Schenk-Hoppé. 2018. Patience is a virtue-In value investing. International Review of Finance. Available online: https:/ / onlinelibrary.wiley.com/doi/10.1111/irfi.12251 (accessed on 1 March 2019).

Ho, Lan-chih, John Cadle, and Michael Theobald. 2013. Portfolio insurance strategies. In Encyclopedia of Finance, 2nd ed. Boston: Springer.

Hommes, Cars. 2013. Behavioral Rationality and Heterogeneous Expectations in Complex Economic Systems. Cambridge: Cambridge University Press.

Hommes, Cars, and Florian Wagener. 2009. Complex evolutionary systems in behavioral finance. In Handbook of Financial Markets: Dynamics and Evolution. Amsterdam: North Holland, Chp. 4, pp. 217-76.

Ioannidis, John. 2005. Why most published research findings are false. PLoS Medicine 8: e124. [CrossRef]

Jacklin, Charles J., Allan W. Kleidon, and Paul Pfeiderer. 1992. Underestimation of portfolio insurance and the crash of October 1987. The Review of Financial Studies 5: 35-63. [CrossRef] 
Jegadeesh, Narasimhan, and Sheridan Titman. 1993. Returns to buying winners and selling losers: Implications for stock market efficiency. The Journal of Finance 48: 65-91. [CrossRef]

Johnson, Ben, Hortense Bioy, and Dimitar Boyadzhiev. 2016. Assessing the true cost of strategic-beta ETFs. The Journal of Index Investing 7: 35-48. [CrossRef]

Katz, Michael L., and Carl Shapiro. 1985. Network externalities, competition, and compatibility. The American Economic Review 75: 424-40.

Kirman, Alan. 1993. Ants, rationality, and recruitment. The Quarterly Journal of Economics 108: 137-56. [CrossRef]

Leland, Hayne E. 1980. Who should buy portfolio insurance? The Journal of Finance 35: 581-94. [CrossRef]

Li, Feifei, and John West. 2017. Live from Newport Beach. It's Smart Beta! Research Affiliates, August 24.

Lux, Thomas. 2009. Stochastic behavioral asset-pricing models and the stylized facts. In Handbook of Financial Markets: Dynamics and Evolution. Amsterdam: North Holland, Chp. 3, pp. 161-215.

Malkiel, Burton G. 2013. Asset management fees and the growth of finance. Journal of Economic Perspectives 27: 97-108. [CrossRef]

Michel-Kerjan, Erwann O. 2010. Catastrophe economics: The national flood insurance program. Journal of Economic Perspectives 24: 165-86. [CrossRef]

NBIM. 2009. Systematic Risk in the Equity Portfolio. Annual Report 2008. Oslo: Norges Bank Investment Management.

Norris, Floyd. 2012. A Computer Lesson Still Unlearned. The New York Times, October 19.

Novy-Marx, Robert. 2013. The other side of value: The gross profitability premium. Journal of Financial Economics 108: 1-28. [CrossRef]

Novy-Marx, Robert. 2014. Predicting anomaly performance with politics, the weather, global warming, sunspots, and the stars. Journal of Financial Economics 112: 137-46. [CrossRef]

Novy-Marx, Robert. 2015. Backtesting Strategies Based on Multiple Signals. Cambridge: National Bureau of Economic Research.

Olsen, Robert A. 1996. Implications of herding behavior for earnings estimation, risk assessment, and stock returns. Financial Analysts Journal 52: 37-41. [CrossRef]

Opler, Tim C., and Sheridan Titman. 1994. Financial distress and corporate performance. The Journal of Finance 49: 1015-40. [CrossRef]

Reinganum, Marc R. 1981. Misspecification of capital asset pricing. Journal of Financial Economics 9: 19-46. [CrossRef]

Rennison, Joe, and Robin Wigglesworth. 2017. No End in Sight for Passive Boom, Says Investing Pioneer. Financial Times, November 14.

Robeco. 2017. Factor Investing Challenges: Factor Timing. Factor Investing Challenges, August 29.

Robeco. 2018. Guide to Factor Investing in Equity Markets. Insight, June 1.

Roider, Andreas, and Andrea Voskort. 2016. Reputational herding in financial markets: A laboratory experiment. Journal of Behavioral Finance 17: 244-66. [CrossRef]

Rosenberg, Barr, Kenneth Reid, and Ronald Lanstein. 1985. Persuasive evidence of market inefficiency. The Journal of Portfolio Management 11: 9-16. [CrossRef]

Russell. 2018. Smart Beta: 2018 Global Survey Findings from Asset Owners. London: FTSE Russell.

Scharfstein, David S., and Jeremy C. Stein. 1990. Herd behavior and investment. The American Economic Review 80: 465-79.

Sgroi, Daniel. 2003. The right choice at the right time: A herding experiment in endogenous time. Experimental Economics 6: 159-80. [CrossRef]

Sharpe, William F. 1964. Capital asset prices a theory of market equilibrium under conditions of risk. The Journal of Finance 19: 425-42.

Sharpe, William F. 1994. The Sharpe ratio. The Journal of Portfolio Management 21: 49-58. [CrossRef]

Shiller, Robert J. 1988. Portfolio insurance and other investor fashions as factors in the 1987 stock market crash. NBER Macroeconomics Annual 3: 287-97. [CrossRef]

Shiller, Robert J. 2010. Irrational Exuberance. Princeton: Princeton University Press.

Singh, Abhay K., David E. Allen, and Powell J. Robert. 2013. Extreme market risk and extreme value theory. Mathematics and Computers in Simulation 94: 310-28. [CrossRef]

Smith, Vernon L., Gerry L. Suchanek, and Arlington W. Williams. 1988. Bubbles, crashes, and endogenous expectations in experimental spot asset markets. Econometrica 56: 1119-51. [CrossRef] 
Sundstrom, Geraldine. 2018. GIS Dynamic Multi-Asset Fund: Flexibility Amid Opportunities and Risks. Strategy Spotlight, July 7.

Tesfatsion, Leigh, and Kenneth Judd, eds. 2006. Handbook of Computational Economics, Volume 2, Agent-Based Computational Economics. Amsterdam: North Holland.

Thaler, Richard. 1987a. Anomalies: Seasonal movements in security prices ii: Weekend, holiday, turn of the month, and intraday effects. Journal of Economic Perspectives 1: 169-77. [CrossRef]

Thaler, Richard. 1987b. Anomalies: The January effect. Journal of Economic Perspectives 1: 197-201. [CrossRef]

Titman, Sheridan, K. C. John Wei, and Feixue Xie. 2004. Capital investments and stock returns. Journal of Financial and Quantitative Analysis 39: 677-700. [CrossRef]

Wasserstein, Ronald L., and Nicole A. Lazar. 2016. The ASA's statement on p-values: Context, process, and purpose. The American Statistician 70: 129-33. [CrossRef]

Welch, Ivo. 2000. Herding among security analysts. Journal of Financial Economics 58: 369-96. [CrossRef]

Wermers, Russ. 1999. Mutual fund herding and the impact on stock prices. The Journal of Finance 54: 581-622. [CrossRef]

Wiggins, Russ. 2018. Smart Beta Is Making This Strategist Sick. Institutional Investor, February 13.

Zwiebel, Jeffrey. 1995. Corporate conservatism and relative compensation. Journal of Political Economy 103: 1-25. [CrossRef]

(C) 2019 by the authors. Licensee MDPI, Basel, Switzerland. This article is an open access article distributed under the terms and conditions of the Creative Commons Attribution (CC BY) license (http:/ / creativecommons.org/licenses/by/4.0/). 